DOI: http://dx.doi.org/10.33846/ghs6106

\title{
Penyuluhan Kesehatan Metode Brain Storming dengan Media Booklet Meningkatkan Pengetahuan dan Sikap Pencegahan DBD Ibu Rumah di Kota Tual
}

Ivonne A.V. Gasper (koresponden)

Program Studi Keperawatan Tual Poltekkes Kemenkes Maluku; ivonavgasper@gmail.com

John D. Haluruk

Program Studi Keperawatan Tual Poltekkes kemenkes Maluku; halurukpromkes@gmail.com

\section{ABSTRAK}

Pada umumnya kasus DBD terjadi pada anak usia $1-15$ tahun. Anak merupakan kelompok yang rentan terhadap penyakit karena itu anak memerlukan dukungan orang tua terutama ibu dalam perawatan kesehatan. Orang tua memerlukan dukungan informasi tentang pencegahan penyakit agar dapat menerapkan pada keluarga. Informasi kesehatan pada masyarakat dapat diperoleh melalui pemberian Penyuluhan. Penelitian ini bertujuan untuk mengetahui pengaruh penyuluhan kesehatan dengan metode brain storming dan media booklet terhadap pengetahuan dan sikap pencegahan DBD pada ibu rumah tangga. Disain penelitian ini adalah quasy eksperimen dengan pendekatan pretest posttest control with group design. Pengambilan sampel menggunakan teknik purposive sampling, jumlah sampel sebanyak 15 orang pada kelompok intervensi dan 15 orang pada kelompok kontrol. Penilaian pengetahuan dan sikap dinilai menggunakan kuisioner yang dirancang peneliti dan diawali dengan pengujian validitas dan reliabiitas. Hasil analisis menunjukkan terdapat pengaruh penyuluhan dengan metode brain storming dan media booklet terhadap pengetahuan dan sikap pencegahan DBD. (masing-masing $p$ value $=0,000$ dan $0,006<\alpha 0,05$ ). Penyuluhan kesehatan dengan metode brain storming dan media booklet dapat dijadikan sebagai salah satu intervensi dalam meningkatkan pengetahuan dan sikap pencegahan DBD.

Kata kunci: penyuluhan kesehatan; brain storming; booklet; DBD; pengetahuan; sikap

\section{PENDAHULUAN}

\section{Latar Belakang}

Demam dengue (DD) dan demam berdarah dengue (DBD) adalah penyakit demam akut yang dapat menyebabkan kematian (1). Perjalanan klinis DBD dimulai dari peningkatan suhu tubuh secara mendadak disertai facial flush dan gejala lain seperti anoreksia,muntah, nyeri kepala, nyeri otot dan nyeri sendi. Fase kritis penyakit ini adalah terjadi kebocoran plasma saat transisi fase febris ke afebris (2). Dengue ditularkan oleh genus aedes, nyamuk yang tersebar luas di daerah tropis dan subtropis termasuk Indonesia.

Setiap tahun hampir 390 juta orang di dunia terinfeksi DBD. Di Indonesia kasus DBD tahun 2016 sebanyak 2014.171 kasus, meninggal 1.598 dan angka kesakitan/ insidence rate (IR) 78,85 per 100.000 penduduk, tahun 2017 sebanyak 68.407 kasus dan meninggal 493 orang serta IR 26,12 per 100.000 penduduk ${ }^{(3)}$. Tahun 2018 kasus DBD berjumlah 65.602 kasus, dengan jumlah kematian sebanyak 467 orang dan IR sebanyak 24,75 per 100.000 penduduk ${ }^{(4)}$

Upaya peningkatan pemberdayaan dan peran serta masyarakat masih menjadi strategi prioritas dalam upaya pencegahan dan pengendalian DBD karena salah satu faktor yang menyebabkan peningkatan kasus DBD di Indonesia adalah perilaku masyarakat ${ }^{(5)}$. Hasil penelitian Dharmasuari dan Sudarmaja (2019) mendapatkan adanya hubungan signifikan antara perilaku pencegahan dan kejadian DBD ${ }^{(6)}$

Perilaku adalah respons atau reaksi seseorang terhadap stimulus. Perubahan perilaku dalam diri seseorang dapat terjadi melalui proses belajar ${ }^{(7)}$. Salah satu bentuk intervensi untuk merubah perilaku adalah melalui pendidikan kesehatan atau penyuluhan kesehatan. Penyuluhan kesehatan dapat diberikan pada kelompok besar dan kelompok kecil. Pada kelompok kecil yang jumlah pesertanya kurang dari 15 orang dapat menggunanakan metode brain storming ${ }^{(8)}$. Brain storming atau curah pendapat merupakan metode pengajaran inovatif yang memotivasi, meningkatkan ketrampilan berpikir dan prestasi belajar peserta didik ${ }^{(9)}$. Selain metode penyuluhan, pemilihan media penyuluhan juga dapat menunjang tercapainya tujuan penyuluhan. Salah satu media yang baik adalah booklet. Booklet adalah media berbentuk buku kecil yang berisi tulisan atau gambar yang memiliki keunggulan dibandingkan media visual yang lain ${ }^{(10)}$. 
DBD pada umumnya menyerang anak di bawah usia 15 tahun ${ }^{(3)}$. Berdasarkan data dari Dinas Kesehatan Kota Tual, semua kasus DBD di kota Tual adalah anak usia 1-12 tahun. Pada tahun 2016 terdapat 29 kasus DBD dan yang meninggal 7 orang, tahun 2017 berjumlah 118 kasus, meninggal 2 orang serta tahun 2018 terdapat 52 kasus dan meninggal 2 orang. Hasil Susenas 2018 menunjukkan bahwa anak usia 0-17 tahun yang mengalami keluhan kesehatan sebesar 31,59 persen. Anak yang mengalami keluhan kesehatan dan mengakibatkan terganggunya pekerjaan, sekolah, atau kegiatan sehari-hari (sakit) sebesar 15,89 persen (11).

Kasus DBD yang umumnya menyerang anak menjadi tantangan bagi orang tua agar tetap memperhatikan kesehatan anak. Orang tua, khususnya ibu adalah faktor yang sangat penting dalam mewariskan status kesehatan kepada anak-anak mereka. Rendahnya kesehatan orang tua terutama ibu, bukan hanya karena status sosial ekonominya rendah tetapi sering juga disebabkan orang tua atau ibu tidak mengetahui bagaimana cara memelihara kesehatannya. Oleh karena itu penyuluhan kesehatan pada orang tua khususnya ibu sangat diperlukan agar dapat menambah pengetahuan serta menimbulkan kesadaran melakukan kebiasaan hidup sehat yang akan diajarkan pada keturunannya ${ }^{(12)}$ Penyuluhan kesehatan DBD dengan metode brain storming yang dimodifikasikan dengan pemberian booklet akan membantu orang tua untuk lebih memahami penyakit DBD.

Penelitian ini bertujuan untuk mengetahui pengaruh penyuluhan kesehatan dengan metode brain storming dan media booklet terhadap pengetahuan dan sikap pencegahan DBD pada ibu rumah tangga di kota Tual. Diharapkan melalui penelitian ini tenaga kesehatan dapat menggunakan metode dan media penyuluhan yang lebih inovatif dan menarik agar dapat memotivasi dan meningkatkan pengetahan serta ketrampilan dari peserta penyuluhan.

\section{METODE}

Desain penelitian ini adalah quasy eksperimen dengan pendekatan pretest posttest control with group design. Pengambilan sampel menggunakan teknik purposive sampling, sampel dalam penelitian ini adalah ibu rumah tangga yang memenuhi kritria bersedia menjadi responden dengan jumlah sampel sebanyak 15 orang pada kelompok intervensi dan 15 orang pada kelompok kontrol. Penelitian ini dilaksanakan pada bulan Agustus sampai dengan Oktober 2019 di Kelurahan Lodar-El kota Tual. Maluku Tenggara. Pengumpulan data dibagi dalam dua tahap yaitu tahap pretest dan posttest. Analisis bivariat menggunakan Paired t-test (Sampel berpasangan) untuk mengetahui pengaruh penyuluhan kesehatan dengan metode brain storming dan media booklet terhadap pengetahuan dan sikap pada kelompok intervensi dan kelompok kontrol.

\section{HASIL}

Penelitian ini menemukan dari 30 responden mayoritasnya adalah kelompok umur $36-45$ tahun, tingkat pendidikan terakhir SMA dan hampir semua responden tidak bekerja, yang terlihat pada tabel 1.

Tabel 1. Karakteristik responden di kota Tual

\begin{tabular}{|c|c|c|c|c|}
\hline \multirow{2}{*}{ Karakteristik } & \multicolumn{2}{|c|}{ Kelompok intervensi } & \multicolumn{2}{c|}{ Kelompok kontrol } \\
\cline { 2 - 5 } & Frekuensi (n) & Persentase (\%) & Frekuensi (n) & Persentase (\%) \\
\hline Umur: & & & & \\
$25-35$ & 5 & 33,3 & 2 & 13,3 \\
$36-45$ & 10 & 66,7 & 4 & 26,7 \\
$46-56$ & 0 & 0 & 9 & 60,0 \\
\hline Pendidikan terakhir & & & & \\
SMP & 2 & 13,3 & 0 & 0.00 \\
SMA & 5 & 33,4 & 14 & 93,3 \\
PT & 8 & 53,3 & 1 & 6.7 \\
\hline Pekerjaan: & & & & \\
Bekerja & 7 & 46,7 & 2 & 13,3 \\
Tidak Bekerja & 8 & 53,3 & 13 & 86,7 \\
\hline
\end{tabular}

Sedang pada tabel 2 dan tabel 3 memperlihatkan perbedaan nilai mean pengetahuan dan sikap baik pada kelompok intervensi maupun kontrol setelah diberi penyuluhan kesehatan yaitu pada kelompok intevensi 1,20 dan kelompok kontrol 1,26. 
Tabel 2. Pengetahuan DBD pada kelompok intervensi dan kontrol di kota Tual

\begin{tabular}{|c|c|c|c|c|c|c|}
\hline \multirow{2}{*}{ Pengetahuan } & \multicolumn{3}{|c|}{ Intervensi } & \multicolumn{3}{c|}{ Kontrol } \\
\cline { 2 - 7 } & Mean & Min & Max & Mean & Min & Max \\
\hline Pre test & 7,47 & 3 & 10 & 6,93 & 5 & 9 \\
\hline Post test & 8,67 & 7 & 11 & 7,67 & 5 & 11 \\
\hline
\end{tabular}

Tabel 3. Sikap pencegahan DBD pada kelompok intervensi dan kontrol di kota Tual

\begin{tabular}{|c|c|c|c|c|c|c|}
\hline \multirow{2}{*}{ Sikap } & \multicolumn{3}{|c|}{ Intervensi } & \multicolumn{3}{c|}{ Kontrol } \\
\cline { 2 - 7 } & Mean & Min & Max & Mean & Min & Max \\
\hline Pre test & 46,40 & 34 & 53 & 44,67 & 36 & 54 \\
\hline Post test & 50,47 & 45 & 56 & 52,33 & 44 & 61 \\
\hline
\end{tabular}

Hasil uji statistik paired t- test pada kelompok intervensi dan kontrol terlihat pada tabel 4 dan tabel 5 , yaitu $t$ value pengetahuan pada kelompok intervensi $0,006(<0,05)$ Ho di tolak, yang berarti ada perbedaan signifikan sebelum dan sesudah diberikan intervensi sedang pada kelompok kontrol $t$ value 0,068 ( $>0.05$ ) Ho diterima, yang berarti bahwa tidak ada perbedaan signifikan pengetahuan sebelum dan sesudah penyuluhan pada kelompok kontrol. Sedang $t$ value sikap pada kelompok intervensi dan kontrol masing-masing adalah 0,000 $(<0,05)$ Ho di tolak, yang berarti ada perbedaan signifikan sikap sebelum diberikan penyuluhan dan setelah diberikan penyuluhan kesehatan.

Tabel 4. Paired t-test pengetahuan

\begin{tabular}{|c|c|c|c|}
\hline Pengetahuan Kel Intervensi & Mean & $t$ value & Hasil \\
\hline Sebelum Penyuluhan & 7,47 & 0,006 & Ho Ditolak \\
sesudah Penyuluhan & 8,67 & & \\
\hline Pengetahuan Kel Kontrol & Mean & $t$ value & Hasil \\
\hline Sebelum Penyuluhan & 6,93 & 0,068 & Ho Diterima \\
Sesudah Penyuluhan & 7,67 & & \\
\hline
\end{tabular}

Tabel 5. Paired t-test sikap

\begin{tabular}{|c|c|c|c|}
\hline Sikap Kel Intervensi & Mean & $t$ value & Hasil \\
\hline Sebelum Penyuluhan & 46,40 & 0,000 & Ho Ditolak \\
sesudah Penyuluhan & 50,47 & & \\
\hline Sikap Kel Kontrol & Mean & $t$ value & Hasil \\
\hline Sebelum Penyuluhan & 44,67 & 0,000 & Ho Ditolak \\
Sesudah Penyuluhan & 52,33 & & \\
\hline
\end{tabular}

\section{PEMBAHASAN}

Hasil penelitian menunjukkan pengetahuan responden pada kelompok intervensi dan kelompok kontrol meningkat setelah diberikan penyuluhan meski diberi perlakuan yang berbeda pada kedua kelompok. Hasil penelitian ini mendukung hasil penelitian Kusumawardhani (2012) yaitu ada pengaruh penyuluhan terhadap tingkat pengetahuan dan praktik ibu dalam pencegahan DBD pada anak ${ }^{(13)}$. Penelitian N Setiowati (2017) mendapatkan ada pengaruh penyuluhan terhadap perilaku pencegahan DBD pada ibu-ibu di Keluhan Ngampilan Yogyakarta dengan taraf signifikasi 0.000 (14) Menurut Notoatmodjo (2012) semua bentuk penyuluhan kesehatan dapat meningkatkan pengetahuan masyarakat dan satu diantaranya adalah adalah brain storming ${ }^{(8)}$. Hasil penelitian Triharini, Mira, Zahra, Halimatus 2017) mendapatkan metode brain storming dapat merubah perilaku (pengetahuan, sikap dan tindakan) ${ }^{(15)}$. Brain storming atau curah pendapat adalah metode pendidikan kesehatan yang digunakan pada kelompok kecil serta merupakan modifikasi metode diskusi Pada metode ini 
setiap peserta dapat menyampaikan ide atau pendapatnya secara bebas ${ }^{(8)}$. Pengalaman yang peneliti dapatkan pada saat memberikan penyuluhan yaitu peserta kelompok intervensi sangat aktif dalam memberikan ide atau pendapatnya namun pada kelompok kontrol keaktifan peserta sangat kurang. Menurut peneliti metode brain storming yang digunakan pada saat penyuluhan sangat baik karena dapat mendorong peserta untuk berbicara atau menyampaikan pendapatnya terhadap topik yang didiskusikan.

Hasil analisis uji dua kelompok beda berpasangan pada kelompok intervensi menunjukkan bahwa penyuluhan kesehatan yang dilakukan dengan metode brain storming dan media booklet efektif meningkatkan pengetahuan ibu rumah tangga sedang pada kelompok kontrol tidak bermakna. Hasil penelitian ini mendukung hasil penelitian M. Syafi'udin, Wantiyah, Kushariyadi (2018) yaitu pendidikan kesehatan menggunakan media booklet dapat meningkatkan pengetahuan DBD pada keluarga ${ }^{(16)}$. Hasil penelitian Setiawan, Ridwan, Iryanti , Muryati ( 2020) juga mendapatkan penggunaan booklet sebagai media edukasi berhubungan dengan meningkatnya pengetahuan mengenai premenopause dan efikasi diri ${ }^{\left({ }^{17}\right)}$. Booklet memiliki keunggulan dibandingkan media visual yang lain ${ }^{(10)}$. Menurut peneliti booklet yang diberikan memungkinkan kelompok intervensi membaca secara berulang sehingga dapat membantu responden dalam mengingat dan memahami materi yang diberikan maka secara tidak langsung akan meningkatkan pengetahuan. Pengetahuan adalah hasil tahu yang terjadi setelah seseorang melakukan penginderaan terhadap suatu objek tertentu, penginderaan terjadi melalui indera penglihatan, pendengaran, penciuman, rasa dan raba, namun sebagian besar $^{(8)}$.

Penyuluhan dapat diartikan sebagai suatu sistem pendidikan non formal untuk merubah perilaku (pengetahuan, sikap dan ketrampilan) seseorang agar mampu berperan sesuai dengan kedudukannya dalam mengatasi masalah yang dihadapinya. Berdasarkan hasil penelitian diketahui bahwa rerata sikap pretest pada kelompok intervensi lebih tinggi dari kontrol sedangkan posttest sikap kelompok kontrol lebih dari kelompok intervensi. Hasil analisis uji dua kelompok beda berpasangan menunjukkkan bahwa ada pengaruh penyuluhan terhadap sikap pencegahan DBD pada kelompok intervensi dan kontrol.

Menurut peneliti, meskipun kelompok kontrol diberikan penyuluhan secara ceramah tanpa brain storming dan tanpa pemberian booklet, namun sikap pencegahan DBD pada kelompok kontrol dapat terbentuk oleh karena berbagai faktor diantaranya adanya informasi atau pengetahuan yang diperoleh setelah menndapatkan penyuluhan, maupun oleh hal lain seperti informasi melalui media sosial, media cetak dan elektronik, dan lain sebagainya ${ }^{(8)}$. Notoatmodjo (2012) mengungkapkan bahwa sikap sering diperoleh dari pengalaman sendiri atau dari orang lain yang paling dekat, selain itu sikap juga di pengaruhi oleh orang penting sebagai referensi maupun sumber daya yang tersedia. Hasil penelitian ini sejalan dengan penelitian Natalansia, Yongwan (2019) yang mendapatkan adanya perbedaan signifikan pengetahuan dan sikap jumantik DBD setelah mendapat penyuluhan kesehatan melalui media booklet ${ }^{(18)}$.

\section{KESIMPULAN}

Penyuluhan kesehatan dengan metode brain storming dan media Booklet efektif meningkatkan pengetahuan dan sikap pencegahan demam berdarah dengue (DBD) pada ibu rumah tangga di kota Tual.

Untuk itu disarankan agar tenaga kesehatan khususnya di kota Tual kiranya dapat mempertimbangkan penggunaan metode brain stroming dan menggunakan media booklet pada saat memberikan penyuluhan kesehatan dan bagi peneliti selanjutnya kiranya dapat mengembangkan penelitian tentang penyuluhan kesehatan pada kelompok besar menggunakan metode dan media penyuluhan lain.

\section{DAFTAR PUSTAKA}

1. Soedarto S. Demam berdarah dengue (dengue haemorrhagic fever). jakarta: Sagung seto; 2012.

2. Aryati A. Buku ajar demam berdarah dengue tinjauan laboratorius edisi II. surabaya: Airlangga university press; 2017.

3. Kementerian kesehatan republik indonesia. Situasi penyakit demam berdarah di indonesia tahun 2017 [Internet]. jakarta: Pusat data dan informasi kementerian kesehatan republik indonesia; 2018. Available from: https://pusdatin.kemkes.go.id/

4. Kementerian kesehatan republik indonesia. Profil kesehatan Indonesia tahun 2018 [Internet]. jakarta: Kementerian kesehatan republik indonesia; 2019. Available from: https://www.kemkes.go.id/ 
5. Kementerian kesehatan republik indonesia. Pedoman pencegahan dan pengendalian demam berdarah dengue di indonesia. jakarta: Ditjen pengendalian penyakit dan penyehatan lingkungan; 2017. 128 p.

6. Dharmasuari MS SI. Hubungan pengetahuan dan perilaku pencegahan DBD terhadap kejadian DBD di desa pemucutan klod. kecamatan denpasar barat. E-Jounal Med [Internet]. 2019;8(4). Available from: issn: 2303-1395 E-Jurnal medika. 8 no.4 april, 2019https://ojs.unud.ac.id/index.php/eum

7. Kholid A. Promosi kesehatan dengan pendekatan teori perilaku, media dan aplikasinya. jakarta: PT rajagrafindo persada.; 2012. $157 \mathrm{p}$.

8. Notoatmodjo S. Promosi kesehatan dan perilaku kesehatan (edisi revisi 2012). jakarta: Rineka cipta.; 2012. $260 \mathrm{p}$.

9. Mohammad KH. Effect of brainstorming strategy on balqa applied university's students' achievement in the course "E 101" and its relation to some variables. An Int peer-reviewed J. 2016;20:81-6.

10. Kurnianingsih $\mathrm{M}$. Efektivitas penggunaan kombinasi media audio visual dan booklet dibanding media booklet terhadap pengetahuan toilet training pada ibu yang memiliki balita. smart Med $\mathrm{J}$. 2019;2(1):1.

11. T W, AH Y, S N, S L, R S, F H. Profil anak indonesia 2018 [Internet]. Romadhon et all, editor. jakarta: Kementerian pemberdayaan Perempuan dan perlindungan anak (KPPPA); 2019. xxvi + 378 halaman. Available from: https://kemenpppa.go.id/

12. Notoatmodjo. S. Promosi kesehatan \& ilmu perilaku. jakarta: Rineka cipta.; 2007. $x+249$.

13. Kusumawardani E, Arkhaesi N, Hardian H. Pengaruh penyuluhan kesehatan terhadap tingkat pengetahuan, sikap dan praktik ibu dalam pencegahan demam berdarah dengue pada anak. $\mathrm{J}$ Kedokt diponegoro. 2012;1(1):104456.

14. Setiowati NA. Pengaruh penyuluhan demam berdarah dengue (DBD) terhadap perilaku pencegahan DBD pada ibu-ibu di RT 40 RW 08 kelurahan ngampilan kecamatan ngampilan yogyakarta. 2017; Available from: http://digilib.unisayogya.ac.id/

15. Triharini M, Pradanie R, Zahra H. Brain storming dan demonstrasi merubah perilaku ibu terhadap pemberian makanan tambahan. J Ners [Internet]. 2017;4(2):161-7. Available from: https://ejournal.unair.ac.id/JNERS/article/view/5029

16. Syafi udin M, Wantiyah W, Kushariyadi K. Pengaruh pendidikan kesehatan metode brainstorming dan video terhadap pengetahuan tentang demam berdarah pada keluarga di wilayah kerja puskesmas puger kabupaten jember. Pustaka Kesehat. 2018;6(1):141.

17. Setiawan R, Iryanti I, Muryati M. Efektivitas media edukasi audio-visual dan booklet terhadap pengetahuan premenopause, rfikasi diri dan stres pada wanita premenopause di kota bandung. Vol. 2, Perilaku dan promosi kesehatan: Idonesian jurnal of health promotion and behavior. 2020. $1 \mathrm{p}$.

18. Natalansyah N, Nyamin Y. Peran booklet terhadap pengetahuan, sikap, perilaku jumantik-PSN dan keberadaan jentik di panarung kota palangkaraya. J Persat perawat Nas Indones. 2020;4(3):150. 